\title{
QUALIDADE REgIONAL REVELADA PELO Sistema de ACreditaÇão de Cursos UNIVERSITÁRIOS DO MERCOSUl
}

\author{
Regional Quality ReVealed by System of Regional \\ ACCreditation of University Courses of Mercosur
}

\author{
Marianne Pereira de Souza \\ Doutora em Educaçáo - Universidade Estadual de Mato Grosso do Sul (UEMS) \\ Dourados - Mato Grosso do Sul - Brasil \\ ORCID: https://orcid.org/0000-0002-5502-8073 \\ marianne-souza@hotmail.com \\ Giselle Cristina Martins Real \\ Doutora em Educação - Universidade Federal da Grande Dourados (UFGD) \\ Dourados - Mato Grosso do Sul - Brasil \\ ORCID: https://orcid.org/0000-0002-8855-4141 \\ gcreal@terra.com.br
}

\begin{abstract}
Resumo: $\mathrm{O}$ trabalho tem como objeto a concepçáo de qualidade revelada nos resultados do primeiro ciclo do Sistema de Acreditação de Cursos Universitários do Mercosul. A pesquisa documental realizada busca responder ao seguinte problema: o que os resultados do primeiro ciclo revelam sobre a qualidade dos cursos de graduaçáo acreditados pelo Sistema regional? Em síntese, os resultados revelam que a qualidade regional se constitui a partir de parâmetros diversos, e, portanto, não é possível afirmar sobre a existência de um padráo único de qualidade para todos os cursos acreditados e que esteja acima da qualidade nacional dos países integrantes do Sistema. Pode-se inferir que a dimensáo política e social da educação não é prioridade na implementação da acreditação regional, processo que teria como prerrogativa a garantia e a melhoria da qualidade. E, considerando o caráter competitivo da acreditação e do seu modelo de avaliação, alguns países acabam optando por cumprir formalmente os critérios estabelecidos no âmbito regional. Nesses casos, a avaliação passa a ser utilizada para reunir os elementos necessários para atingir os possíveis efeitos regulatórios do Sistema, ou seja, o reconhecimento automático de títulos nos países do Mercosul.
\end{abstract}

Palavras-Chave: Arcu-Sul. Avaliação educacional. Regulação.

ABSTRACT: The work has as object the conception of quality revealed in the results of the first cycle of the System of Regional Accreditation of University Courses of Mercosur. The documentary research conducted seeks to answer the following problem: what do the results of the first cycle reveal about the quality of undergraduate courses accredited by the regional system? In summary, the results show that regional quality is based on different parameters, and therefore it is not possible to affirm that there is a single quality 
standard for all accredited courses that is above the national quality of the member countries of the system. It can be inferred that the political and social dimension of education is not a priority in the implementation of regional accreditation, a process that would have as a prerogative the guarantee and quality improvement. And, considering the competitive nature of accreditation and its assessment model, some countries end up formally meeting the criteria established at the regional level. In such cases, the valuation will be used to gather the elements necessary to achieve the possible regulatory effects of the System, that is, the automatic recognition of titles in Mercosur countries.

KeYwords: Arcu-Sul. Educational evaluation. Regulation.

\section{Introdução}

O presente trabalho tem como objeto a concepçáo de qualidade revelada nos resultados do primeiro ciclo do Sistema de Acreditaçáa ${ }^{1}$ de Cursos Universitários do Mercosul (Arcu-Sul).

A criação de sistemas de acreditação na América Latina foi impulsionada, dentre outros fatores, pela expansão das matrículas e das instituiçôes de educação superior, realizada especialmente no setor privado (DIAS SOBRINHO, 2008; LAMARRA, 2010; VERHINE; FREITAS, 2012) e a heterogeneidade nos níveis de qualidade e nos sistemas de avaliaçáo dos países (LAMARRA, 2010).

Esse movimento ocorre também porque a qualidade é uma das questốes fundamentais das políticas educacionais tanto em nível local, como em nível regional (AFONSO, 2013; DIAS SOBRINHO, 2008; KNIGHT, 2004; KRAWCZYK; SANDOVAL, 2012; LAMARRA, 2010; VERHINE; FREITAS, 2012) e, embora a literatura considere o seu conceito complexo, amplo e heterogêneo (REAL, 2009; SOUSA, 2009), de um modo geral, está relacionada à avaliaçăo e à regulação ${ }^{2}$ de natureza sistêmica.

Assim, diante da importância dos diplomas de graduação para o bloco econômico, os integrantes do Mercado Comum do Sul (Mercosul) instituíram o Sistema Arcu-Sul, que tem como objetivo a execução da avaliação e acreditação de cursos universitários dos países da região. Segundo o Acordo no $17 / 2008^{3}$, por meio do ato de acreditação, os Estados membros e associados reconhecem mutuamente a qualidade acadêmica dos títulos ou diplomas outorgados por instituiçôes universitárias, cujos cursos de graduação tenham sido acreditados pelo Sistema regional (MERCOSUL, 2008a). 
Observa-se que os integrantes do Mercosul partem da premissa que os resultados da acreditação atestam a qualidade dos cursos e, portanto, são suficientes para o reconhecimento de títulos nos países da regiáo. Contudo, considerando a complexidade que envolve a avaliaçáo da qualidade, especialmente nos países latino-americanos (LAMARRA, 2010), busca-se responder ao seguinte problema: o que os resultados do primeiro ciclo revelam sobre a qualidade dos cursos de graduação acreditados pelo Sistema regional?

Para responder à pergunta, a pesquisa documental realizada focalizou os documentos do Arcu-Sul e, mais especificamente, as resoluçôes de certificação expedidas no primeiro ciclo, que ocorreu no período de 2008 a 2015 e contou com a participação de cursos oriundos da Argentina, Bolívia, Brasil, Chile, Colômbia, Paraguai, Uruguai e Venezuela.

Destaca-se que, neste estudo, a educação é entendida como política social de natureza pública (AZEVEDO, 1997). Portanto, o debate sobre a qualidade educacional "[...] remete à apreensão de um conjunto de determinantes que interferem, nesse processo, no âmbito das relaçôes sociais mais amplas, envolvendo questóes macroestruturais" (DOURADO; OLIVEIRA, 2009, p. 202).

Desse modo, a análise dos documentos é realizada considerando que, de acordo com Demo (1994; 2015), a qualidade decorre de duas dimensóes, a formal e a política. A qualidade política está ligada aos fins, valores e conteúdos, e significa a competência do sujeito para se fazer e fazer história, diante dos fins históricos da sociedade. Por isso, para o autor, o político é o "[...] espaço de atuação do homem, no qual ele forma a si mesmo e molda as circunstâncias objetivas que o cercam” (DEMO, 2015, p. 43).

Já a qualidade formal refere-se à habilidade de manejar meios, instrumentos, formas técnicas e procedimentos e, em vista disso, convém "[...] colocar o lugar adequado da preocupação com a forma, com a instrumentação técnica, com as condiçóes objetivas” (DEMO, 2015, p. 52).

Os resultados da pesquisa estão organizados em dois tópicos, além da introdução e das consideraçôes finais. $\mathrm{O}$ primeiro enfatiza os processos de avaliação e os critérios de qualidade utilizados para a acreditação de cursos no Sistema do Mercosul. O segundo tópico apresenta a concepção de qualidade regional revelada nos resultados do primeiro ciclo do Arcu-Sul. 


\section{Avaliação e qualidade na política de acreditação do Mercosul}

A acreditação no Mercosul é resultado do "[...] processo de avaliação por meio do qual é certificada a qualidade acadêmica dos cursos de graduação estabelecendo que satisfazem o perfil do graduado e os critérios de qualidade previamente aprovados no âmbito regional para cada diploma” (MERCOSUL, 2008a).

O processo de acreditação regional é gerenciado pela Rede de Agências Nacionais de Acreditação (Rana) que, conforme o Acordo no 17/2008, possui o papel de coordenar o Sistema, bem como, definir os critérios de avaliação. Para integrar a Rana, cada país indicou uma Agência Nacional de Acreditaçáo (ANA), totalizando oito agências nacionais, conforme apontado no quadro 1.

PAÍS

Argentina

Brasil

Chile

Colômbia da Rana

\section{AGÊNCIA NACIONAL DE ACREDITAÇÃO}

Comissão Nacional de Avaliação e Acreditação (CONEAU).

Instituto Nacional de Estudos e Pesquisas Anísio Teixeira (INEP). Comissão Nacional de Avaliação da Educação Superior (CONAES). Secretaria de Regulação e Supervisão da Educação Superior (SERES)

Bolívia Comissão Nacional de Acreditação de Carreiras Universitárias (CNACU) Comissão Nacional de Acreditação (CNA). Conselho Nacional de Acreditação (CNA).

Paraguai Agência Nacional de Avaliação e Acreditação Superior (ANEAES)

Uruguai Comissão Ad hoc de Acreditação para administrar o ARCU-SUL.

Venezuela Comitê de Avaliação e Acreditação de Programas e Instituições de Educação Superior (CEAPIES)

Quadro 1: Relação das agências nacionais de acreditação integrantes

Fonte: Elaborado pelas autoras de acordo com dados da página eletrônica do Arcu-Sul (Mercosul, 2016).

De acordo com o Manual de Procedimentos do Sistema, elaborado pela Rana, a participação na acreditação é voluntária e as instituiçôes que 
desejarem inscrever um curso devem enviar uma solicitação à ANA correspondente, apresentando informaçôes e documentos. Posteriormente, os cursos são submetidos aos processos de autoavaliação e avaliação externa.

Cabe ressaltar que, no primeiro ciclo, o Sistema acreditou cursos nas seguintes titulaçôes: agronomia, arquitetura, enfermagem, engenharia, medicina, odontologia e medicina veterinária. Assim, para cada titulação, foram constituídas comissóes consultivas para elaboração de documentos que respaldaram os processos de avaliação.

A autoavaliação requer um conjunto de ações, por meio das quais o curso candidato à acreditação verifica o grau em que se ajusta aos critérios de qualidade estabelecidos e acordados, e indica o grau em que alcança suas próprias metas e propósitos (MERCOSUL, 2008b).

Para tanto, cada curso deve ter como referência as guias de autoavaliação de cursos, elaboradas para cada titulação, e as disposiçôes sobre a sua implementaçáo pela ANA. Os resultados desse processo devem fazer parte do informe de autoavaliação que será enviado pelo curso para a realização dos procedimentos restantes. Segundo as guias de autoavaliação, esse documento deve ser elaborado com as seguintes propriedades:

1. Técnico: se fundamenta en recursos metodológicos válidos y en información confiable.

2. Representativo: expresa el trabajo y participación de la comunidad académica correspondiente.

3. Analítico: va más allá de la mera descripción de las situaciones detectadas y de las estimaciones subjetivas, identificando causas y efectos.

4. Equilibrado: toma en cuenta tanto los logros cuanto los aspectos deficitarios y los pondera adecuadamente.

5. Realista: en cuanto al plan de mejoramiento y a las proyecciones futuras (MERCOSUL, 2008c).

Percebe-se que as propriedades estabelecidas para a elaboração do informe preconizam que a autoavaliação tenha um caráter permanente e participativo, e expresse o trabalho da comunidade acadêmica, tanto no que diz respeito aos problemas encontrados, como ao planejamento de melhorias. 
Segundo a literatura da área, essas características permeiam a perspectiva formativa e emancipatória da autoavaliação, que precisa ser pensada na interseção entre as intençôes e as realizações (BELLONI et al, 2000; DIAS SOBRINHO, 2003).

Para que a autoavaliação tenha um caráter participativo, deve contar com autonomia da comunidade acadêmica, pois os valores fundamentais desse processo pertencem aos participantes. E, para Santos (2011), a própria avaliação também é um processo de aprendizagem política e de construção de autonomias dos atores e das instituiçôes.

Nessa perspectiva, Santos (2011, p. 103) acrescenta que "os modelos de avaliação participativa tornam possível a emergência de critérios de avaliação interna suficientemente robustos para se medirem pelos critérios de avaliação externa”.

Contudo, embora os documentos do Arcu-Sul sinalizem a importância da autoavaliação, uma vez que é a partir desse processo que as etapas de avaliação externa e a emissão da resolução de acreditação são desenvolvidas, observa-se nos documentos a indução de conteúdos e formatos, o que pode comprometer o atendimento às propriedades estabelecidas nas guias de autoavaliação.

Essas informaçôes permitem problematizar o papel desse processo no Sistema e questionar se as reflexóes e discussôes acerca da autoavaliação estão resultando em açóes para resolver os problemas apontados como fragilidades, visando à melhoria da qualidade, como estabelecem os documentos do Arcu-Sul. Ou, se a autoavaliação ocorre como uma ação isolada somente no momento de elaboração do informe.

No Arcu-Sul, a avaliação externa tem como objetivo verificar se o curso cumpre com os critérios de qualidade acordados no âmbito do Sistema, levando em conta, entre outros documentos, o informe de autoavaliação (MERCOSUL, 2008b).

Pode-se verificar que a política regional enfatiza a avaliação externa, definida pelo Manual de Procedimentos do Sistema como o "marco central do processo de avaliação para a Acreditação ARCU-SUL" (MERCOSUL, 2008b).

O Manual de Procedimentos aponta, ainda, que a atividade do Comitê de Pares Avaliadores é chave no processo de acreditação, uma vez que suas opinióes e recomendaçóes, acerca da qualidade do curso, consti- 
tuem uma colaboração externa e independente, que é fundamental para que a ANA constitua seu próprio juízo e elabore a resolução referente à acreditação do curso (MERCOSUL, 2008b). Cabe realçar que a Rana organiza e mantém um Banco de Avaliadores, por titulação, conforme diretrizes acordadas no âmbito da rede.

A ênfase da avaliação externa na educação superior também é objeto de discussão de autores da área como Neave (2012) e Verhine e Freiras (2012), já que a sofisticação dos procedimentos de avaliação é uma forma de atender as demandas do mercado. Diante desse contexto, Verhine e Freitas (2012, p. 24) consideram que "por mais valorizada que seja a avaliação interna independente e voluntária, ela acaba sendo, em boa parte, determinada pela avaliação externa".

Ou seja, o protagonismo da avaliação externa em detrimento da autoavaliaçáo pode comprometer os resultados do processo de acreditação no Arcu-Sul, bem como, a sua própria configuração enquanto Sistema.

Conforme o Manual de Procedimentos, mesmo que o processo termine formalmente com o juízo da ANA, a garantia da qualidade exige o controle o acompanhamento das açôes de melhoria que foram planejadas desde o processo de autoavaliação. Em outras palavras, a autoavaliação não pode ser utilizada apenas para elaborar um diagnóstico do curso, mas deve definir as estratégias para a melhoria da sua qualidade.

Contudo, o que se verifica no Arcu-Sul é a minimização da perspectiva formativa e do caráter emancipatório da autoavaliação, uma vez que se busca no âmbito da Rana induzir os cursos a utilizarem modelos preestabelecidos por meio de documentos, instrumentos e relatórios padronizados. Além disso, a ênfase na avaliação externa pode afetar características imprescindíveis do processo como a autonomia, a reflexão e a participação de todos os atores envolvidos e, consequentemente, impactar os objetivos da acreditação.

Ao término dos processos de avaliação, a ANA correspondente é responsável pela emissão da resolução que poderá certificar ou não certificar a acreditaçáo dos cursos. Conforme o Manual de Procedimentos do Sistema, as resoluçôes serão emitidas em um formato comum, acordado para o Arcu-Sul (MERCOSUL, 2008b). 
Diante disso e da necessidade de mecanismos para assegurar a validez das resoluções de acreditação, percebe-se o empenho dos integrantes da Rana para padronizar os procedimentos, as técnicas e os documentos, uma vez que embora os documentos assinalem a necessidade de se respeitar as especificidades dos países e a autonomia das instituiçóes, a acreditação no Arcu-Sul objetiva estabelecer um padrão de qualidade regional. Todavia, esse processo se torna conflituoso diante de sistemas nacionais tão heterogêneos (LAMARRA, 2010).

As comissóes consultivas formadas pela Rana também elaboraram os critérios regionais de qualidade para cada uma das titulaçóes, entre os anos de 2008 e 2010. Para tanto, consideraram obrigatoriamente quatro dimensóes - contexto institucional, projeto acadêmico, comunidade universitária e infraestrutura - sendo que, em cada dimensão, são indicados os componentes a serem avaliados, apresentados no quadro 2.

\begin{tabular}{|c|c|c|c|}
\hline $\begin{array}{c}\text { Contexto } \\
\text { institucional }\end{array}$ & $\begin{array}{c}\text { Projeto } \\
\text { acadêmico }\end{array}$ & $\begin{array}{c}\text { Comunidade } \\
\text { universitária }\end{array}$ & Infraestrutura \\
\hline $\begin{array}{c}\text { Características do } \\
\text { curso e sua inserção } \\
\text { institucional }\end{array}$ & Plano de estudos & Estudantes & $\begin{array}{c}\text { Infraestrutura } \\
\text { física e logística }\end{array}$ \\
\hline $\begin{array}{c}\text { Organização, } \\
\text { governo, gestão e } \\
\text { administraçáo do } \\
\text { curso }\end{array}$ & $\begin{array}{c}\text { Processos } \\
\text { de ensino } \\
\text { aprendizagem }\end{array}$ & Graduados & Biblioteca \\
\hline $\begin{array}{c}\text { Sistemas de avaliaçãó } \\
\text { do processo de gestáo }\end{array}$ & $\begin{array}{c}\text { Investigação e } \\
\text { desenvolvimento } \\
\text { tecnológico }\end{array}$ & Docentes & $\begin{array}{c}\text { Instalaçóes, } \\
\text { laboratórios, } \\
\text { campos e } \\
\text { instalaçôes } \\
\text { experimentais }\end{array}$ \\
\hline $\begin{array}{c}\text { Políticas e Programas } \\
\text { de bem-estar } \\
\text { institucional }\end{array}$ & $\begin{array}{c}\text { Extensão, } \\
\text { vinculação e } \\
\text { cooperaçáo }\end{array}$ & Pessoal de apoio & \\
\hline
\end{tabular}

Quadro 2: Relação dos componentes, por dimensão, definidos pelo Sistema ARCU-SUL

Fonte: Elaborado pelas autoras, a partir dos documentos de critérios do Sistema ARCUSUL (2016). 
Ressalta-se que a Rana unificou os componentes apenas para a dimensão contexto institucional. No que diz respeito às demais dimensôes, para a elaboração do quadro 2 , foram considerados os componentes identificados na maior parte dos documentos de critérios analisados. Destacase que a dimensão infraestrutura é a que possui a menor quantidade de componentes comuns às titulaçóes.

Para cada um dos componentes foram estabelecidos os critérios de qualidade por meio dos quais o curso deve formular um juízo sobre o seu grau de cumprimento (MERCOSUL, 2008b). Registra-se que, para as dimensóes projeto acadêmico, comunidade universitária e infraestrutura, as comissóes consultivas apresentaram, também, indicadores para cada um dos critérios de qualidade.

A definição de critérios e indicadores comuns de qualidade para os cursos da regiáo está prevista desde os primeiros planos do Setor Educacional do Mercosul (SEM). Para tanto, segundo o Acordo que instituiu o Arcu-Sul, os critérios regionais seriam aqueles "requeridos para a promoção do desenvolvimento econômico, social, político e cultural" (MERCOSUL, 2008a, p. 2).

Contudo, Souza (2016) afirma que o Sistema mercosulino prioriza os aspectos formais da qualidade, pois enfatiza os instrumentos e métodos, no sentido de perfeição metodológica, desprendida do conteúdo que busca qualificar. Para a autora, essa evidência está na essência dos critérios próprios do mercado e foi constatada pela autora nos indicadores relacionados à/ao:

- gestão institucional, que foi concebida a partir da vertente gerencialista;

- avaliação em seu sentido de verificação de dados e informaçóes quantificáveis;

- perfil e atuação do egresso, com foco no mercado de trabalho;

- projeto pedagógico com predominância nas atividades de ensino, em detrimento da pesquisa e da extensão e

- infraestrutura física desassociada dos padrôes de acessibilidade (SOUZA, 2016, p. 141-142).

A evidência da relação da qualidade dos cursos universitários com mercado de trabalho é apontada por Enguita (1994) como uma das lógicas 
associadas ao conceito de qualidade na educação. Entretanto, a política regional também explicita que os critérios regionais devem ser aqueles que promovam também o desenvolvimento social, político e cultural.

De acordo com Souza (2016) aspectos políticos que permeiam as concepçôes de internacionalização, que subjaz à constituição do bloco, e expressos nos documentos do SEM, como a mobilidade, o intercâmbio, tratados e acordos interinstitucionais, estão ausentes dos documentos de critérios.

Ressalta-se, contudo, que Griboski e Funghetto (2016) consideram que as políticas de mobilidade e intercâmbio dos estudantes e dos docentes são valorizadas nos documentos de critérios. Para as autoras, a implantação de um sistema permanente de acreditação, busca além da mobilidade acadêmica, "[...] a qualificaçáo do processo de ensino, a valorização do egresso na região, a integração universitária por meio de um padrão de qualidade comum a todos os Estados-Membros e o aumento da competitividade e afirmação do SEM” (GRIBOSKI; FUNGHETTO, 2016, p. 256).

Assim, verifica-se que a literatura apresenta opinióes divergentes acerca da concepção de qualidade preconizada no Mercosul, especialmente no que diz respeito aos aspectos políticos necessários para atender as finalidades do SEM.

Essas divergências demonstram a tensão existente entre a necessidade de se estabelecer um padrão de qualidade, baseada em uma lógica de competição de mercado, e o compromisso de elaborar políticas educacionais voltadas para a formaçáo de uma consciência de pertinência à regiáo e de uma identidade regional.

Diante disso questiona-se: qual é a concepção de qualidade revelada nas resoluções de acreditação do Sistema do Mercosul?

\section{A qualidade regional revelada no primeiro ciclo do Arcu-Sul}

No primeiro ciclo, o ARCU-SUL acreditou duzentos e quarenta e seis cursos de graduação, conforme dados retirados da página eletrônica do Sistema e informados na tabela 1. 
Tabela 1: Quantidade de cursos acreditados no primeiro ciclo do ARCU-SUL, por país e por titulação

\begin{tabular}{|c|c|c|c|c|c|c|c|c|}
\hline & 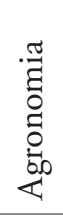 & 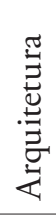 & 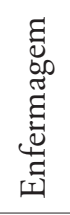 & 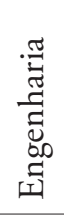 & 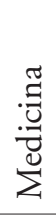 & 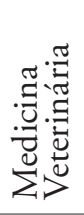 & $\begin{array}{l}\frac{\pi}{00} \\
\frac{0}{0} \\
0 \\
0 \\
0 \\
0\end{array}$ & 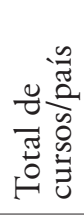 \\
\hline Argentina & 8 & 9 & 4 & 16 & 4 & 8 & 2 & 51 \\
\hline Bolívia & 5 & 5 & 3 & 21 & 7 & 1 & 5 & 47 \\
\hline Brasil & 17 & 8 & 12 & 29 & 1 & 11 & - & 78 \\
\hline Chile & 4 & 1 & 2 & - & 3 & 3 & 2 & 15 \\
\hline Colômbia & 1 & - & - & 6 & 2 & - & - & 9 \\
\hline Paraguai & 1 & 2 & 2 & 7 & 3 & 1 & 1 & 17 \\
\hline Uruguai & 1 & 1 & 1 & 7 & 1 & 1 & 1 & 13 \\
\hline Venezuela & 9 & 4 & - & - & - & 3 & - & 16 \\
\hline Total de cursos & 46 & 30 & 24 & 86 & 21 & 28 & 11 & 246 \\
\hline
\end{tabular}

Fonte: Elaborado pelas autoras a partir dos dados fornecidos na página eletrônica ${ }^{4}$ do Sistema ARCU-SUL e coletados em novembro de 2015 .

Diante da quantidade de cursos acreditados, para análise, foram selecionadas quarenta e seis resoluçóes, das quais: sete são da Argentina, sete da Bolívia, seis do Brasil, seis do Chile, três da Colômbia, sete do Paraguai, sete do Uruguai e três da Venezuela.

Para subsidiar a análise dos documentos, as referências de qualidade estão resumidas, considerando a perspectiva de Demo (1994; 2015), da seguinte forma:

- Dimensão formal (meios/técnicas)

- formato;

- processos avaliativos;

- instrumentos;

- normatizaçóes;

- mínimos quantitativos necessários. 
- Dimensão política (fins)

- articulação com a missão, objetivos e finalidades das instituiçốes;

- atendimento à missão, objetivos e finalidade do SEM;

- atendimento aos objetivos do ARCU-SUL;

- relação ensino-pesquisa-extensão.

Importa lembrar que a acreditação regional foi estruturada a partir de um processo de autoavaliação, para que o curso conheça melhor a sua realidade, identifique suas potencialidades e dificuldades e construa projetos para a sociedade. Portanto, o resultado da avaliaçáo requer a relação das dimensóes formal e política. Contudo, não se pode deixar de mencionar que há no Arcu-Sul uma tendência para utilização da autoavaliação como diagnóstico do curso, ou seja, uma parte do processo, o que compromete a fundamentação de juízo de valores realizado pelas agências nacionais de acreditação.

Em termos gerais, as resoluçóes das agências nacionais de acreditação evidenciam a heterogeneidade dos documentos. Algumas diferenças são percebidas já no formato utilizado pelas agências na elaboração das resoluçôes e estão relacionadas, principalmente, à quantidade de informação disponibilizada. Nesse sentido, foi possível detectar diferenças significativas, especialmente entre os documentos expedidos pela agência argentina e pela agência boliviana.

Para atender ao Manual, as agências nacionais de acreditação devem considerar além do formato das resoluçóes, o conteúdo do informe de autoavaliação e do Comitê de Pares, bem como outros processos de acreditação e antecedentes legais ou de regulação próprios das disposiçôes nacionais.

O quadro 3 apresenta a síntese dos aspectos formais encontrados nas resoluçôes de acreditação do primeiro ciclo do Arcu-Sul.

No que diz respeito à dimensão formal, as agências nacionais atenderam em grande medida às obrigatoriedades expressas nos documentos do Arcu-Sul, uma vez que citaram nas resoluçóes os processos avaliativos desenvolvidos, os instrumentos utilizados e as normatizaçóes. Contudo, a maioria das agências náo considerou necessário mencionar em suas justificativas o atendimento, pelos cursos, aos mínimos quantitativos formais necessários, o que para Gramsci (1974) e Demo (1994) é condição es- 


\begin{tabular}{|c|c|}
\hline $\begin{array}{c}\text { Agência de } \\
\text { acreditaçáo/país }\end{array}$ & Dimensão formal \\
\hline Argentina & $\begin{array}{l}\text { 1. atenção aos aspectos quantitativos do curso } \\
\text { 2. atendimento aos componentes, critérios e indicadores } \\
\text { definidos pelo ARCU-SUL } \\
\text { 3.formato padronizado } \\
\text { 4.legislaçáo nacional e institucional } \\
\text { 5. processos de avaliação realizados }\end{array}$ \\
\hline Bolívia & $\begin{array}{l}\text { 1. atendimento às dimensóes e critérios definidos pelo ARCU-SUL } \\
\text { 2.legislação nacional } \\
\text { 3. processos de avaliação realizados }\end{array}$ \\
\hline Brasil & $\begin{array}{l}\text { 1. atendimento aos critérios e indicadores definidos pelo } \\
\text { ARCU-SUL } \\
\text { 2.formato padronizado } \\
\text { 3. atenção aos dados quantitativos do curso } \\
\text { 4.legislaçáo institucional } \\
\text { 5. processos de avaliação realizados }\end{array}$ \\
\hline Chile & $\begin{array}{l}\text { 1. atendimento aos critérios estabelecidos pelo ARCU-SUL } \\
\text { 2. documentos do ARCU-SUL } \\
\text { 3.formato padronizado } \\
\text { 4. processos de avaliação realizados }\end{array}$ \\
\hline Colômbia & $\begin{array}{l}\text { 1. atenção aos aspectos quantitativos do curso } \\
\text { 2.formato padronizado } \\
\text { 3.processos avaliativos, instrumentos e normatização do } \\
\text { ARCU-SUL }\end{array}$ \\
\hline Paraguai & $\begin{array}{l}\text { 1.características do curso acreditado para cada uma das dimensóes } \\
\text { 2.formato padronizado } \\
\text { 3.normatizaçóes do ARCU-SUL que regulamentam a acreditação } \\
\text { 4. processos de avaliação realizados }\end{array}$ \\
\hline Uruguai & $\begin{array}{l}\text { 1. atendimento aos critérios estabelecidos pelo ARCU-SUL } \\
\text { 2. documentos do ARCU-SUL } \\
\text { 3.formato padronizado } \\
\text { 4. processos de avaliaçáo realizados }\end{array}$ \\
\hline Venezuela & $\begin{array}{l}\text { 1. atendimento aos critérios estabelecidos pelo ARCU-SUL } \\
\text { 2. documentos do ARCU-SUL } \\
\text { 3.formato padronizado } \\
\text { 4. processos de avaliaçáo realizados }\end{array}$ \\
\hline
\end{tabular}

Quadro 3: Síntese dos aspectos formais encontrados nas resoluçóes de acreditaçáo do primeiro ciclo do Arcu-Sul (2009-2014)

Fonte: Elaborado a partir das resoluções de acreditação do primeiro ciclo do ARCU-SUL (2009-20I4). 
sencial para a definição da qualidade. Isso porque, ao optar por critérios imprecisos, a Rana deixou a escolha sobre a indicação dos mínimos quantitativos a cargo das agências.

Observa-se que as agências argentina, brasileira, chilena, paraguaia, uruguaia e venezuelana organizaram o texto das resoluçóes em um modelo padronizado. Os documentos contemplaram as normatizaçóes do ArcuSul que regulamentam a acreditação, os processos de avaliaçáo pelos quais o curso passou para a acreditação, as características do curso acreditado e a resolução final da agência.

Desse modo, pode-se inferir que a qualidade formal foi referenciada nas resoluçóes de acreditação a partir de três aspectos principais: formato dos documentos, atendimento às dimensóes e aos critérios definidos pelo Sistema e processos de avaliaçáo realizados.

Apenas a agência boliviana não apresentou um modelo padronizado, entretanto, no que diz respeito ao conteúdo, as resoluçóes apresentam similaridades que estão relacionadas, principalmente, à dimensão formal da qualidade dos cursos, resumidas na legislação nacional, nos processos avaliativos do Arcu-Sul, no atendimento às dimensóes e critérios e na resolução de acreditaçáo.

Já os aspectos políticos da qualidade dos cursos acreditados estão camente, de algumas titulaçóes, conforme síntese apresentada no quadro 04. Os aspectos considerados com maior incidência foram o intercâmbio e a mobilidade, a participação da comunidade e as políticas de bem-estar e apoio aos estudantes.

Pode-se notar que, nas resoluçóes analisadas, os aspectos políticos utilizados pelas agências nacionais de acreditação incidiram sobre dois focos principais, a articulação com a missão, objetivos e finalidades das instituiçóes e o atendimento à missão, objetivos e finalidade do SEM. Verificase, entretanto, a ausência de aspectos importantes para o atendimento da missão do SEM, como a pertinência mercosulina, necessária para a formaçâo de identidade e cidadania regional.

Observa-se também pouca atenção das agências para o envolvimento da comunidade acadêmica nos processos decisórios dos cursos e até mesmo na própria avaliação. $\mathrm{Na}$ mesma direção, verifica-se que há um descaso das agências de acreditação com a extensão, ainda que, em muitas 


\begin{tabular}{|c|c|}
\hline $\begin{array}{c}\text { Agência de } \\
\text { acreditaçáo/país }\end{array}$ & Dimensão política \\
\hline Argentina & $\begin{array}{l}\text { 1. acessibilidade na infraestrutura } \\
\text { 2. intercâmbio e mobilidade } \\
\text { 3. participação da comunidade universitária } \\
\text { 4. políticas de bem-estar e apoio aos estudantes } \\
\text { 5. planos de cargos e carreiras }\end{array}$ \\
\hline Bolívia & 1. mobilidade (enfermagem) \\
\hline Brasil & $\begin{array}{l}\text { 1. acessibilidade na infraestrutura } \\
\text { 2. compromisso social nos documentos institucionais } \\
\text { 3. intercâmbio e mobilidade } \\
\text { 4. participação da comunidade universitária } \\
\text { 5. planos de cargos e carreiras } \\
\text { 6. políticas de bem-estar e apoio aos estudantes }\end{array}$ \\
\hline Chile & $\begin{array}{l}\text { 1. acessibilidade na infraestrutura (enfermagem, medicina } \\
\text { veterinária, odontologia) } \\
\text { 2. intercâmbio e mobilidade (medicina, medicina veterinária, } \\
\text { arquitetura) } \\
\text { 3. participação da comunidade universitária (medicina veterinária) } \\
\text { 4. políticas de bem-estar e apoio aos estudantes (agronomia, } \\
\text { medicina veterinária) }\end{array}$ \\
\hline Colômbia & $\begin{array}{l}\text { 1. intercâmbio (engenharia) } \\
\text { 2. mobilidade (agronomia e medicina) } \\
\text { 3. participaçáo da comunidade universitária (medicina) } \\
\text { 4. políticas de bem-estar e apoio aos estudantes (agronomia e } \\
\text { medicina) }\end{array}$ \\
\hline Paraguai & $\begin{array}{l}\text { 1.fortalecimento da pesquisa (arquitetura e medicina) e da } \\
\text { extensão (arquitetura) } \\
\text { 2. plano de cargos e carreiras (enfermagem e medicina) }\end{array}$ \\
\hline Uruguai & $\begin{array}{l}\text { 1. compromisso social nos documentos institucionais (enferma- } \\
\text { gem e odontologia) } \\
\text { 2. participação da comunidade universitária (arquitetura e } \\
\text { enfermagem) } \\
\text { 3. acessibilidade na infraestrutura (arquitetura e medicina) } \\
\text { 4. biossegurança (medicina veterinária e odontologia) } \\
\text { 5. integração ensino-pesquisa-extensão (engenharia) }\end{array}$ \\
\hline Venezuela & $\begin{array}{l}\text { 1. intercâmbio e mobilidade (arquitetura e medicina veterinária) } \\
\text { 2. políticas de bem-estar e apoio aos estudantes (agronomia e } \\
\text { medicina veterinária) }\end{array}$ \\
\hline
\end{tabular}

Quadro 4: Síntese dos aspectos políticos encontrados nas resoluçóes de acreditação do primeiro ciclo do ARCU-SUL (2009-2014)

Fonte: Elaborado a partir das resoluções de acreditação do primeiro ciclo do ARCU-SUL (2009-2014). 
resoluçóes, as agências afirmem o compromisso das instituiçóes e dos cursos acreditados com o ensino, a pesquisa e a extensão.

Para Cunha (2014), a natureza da educação universitária tem sido explicitada pelo conceito da indissociabilidade do ensino, da pesquisa e da extensão e, por isso, compreende-se que essa condição se constitui no ponto principal da qualidade. Contudo, essa indissociabilidade não aparece como uma preocupação das agências nacionais de acreditação.

Constata-se, ainda, que há pontos ressaltados por algumas agências que não tiveram o mesmo tratamento por outras, explicitando uma pulverização dos aspectos a serem considerados para a construção de uma concepção comum de qualidade.

Nesse sentido, nota-se nos documentos dos cursos bolivianos e dos cursos paraguaios uma inconsistência sobre os juízos de análise relacionados ao cumprimento dos critérios e dos componentes do Arcu-Sul. Importa mencionar que tanto a Bolívia como o Paraguai constituíram sistemas de avaliação recentemente, para atender ao Mercosul.

$\mathrm{Na}$ resolução destinada ao curso boliviano de agronomia é possível identificar a inconsistência na síntese da avaliação, conforme citação a seguir:

\section{Síntese da avaliação}

O curso de Engenharia Agrônoma da Universidad Autónoma Juan Misael Saracho, ofertado na cidade de Tarija, apresenta as seguintes características para cada uma das dimensôes de avaliação:

a) Contexto institucional: são cumpridos os critérios para os componentes desta Dimensão.

b) Projeto acadêmico: nesta Dimensão há critérios cumpridos integralmente e critérios parcialmente cumpridos.

c) Comunidade Universitária: nesta Dimensão há critérios cumpridos integralmente e critérios parcialmente cumpridos.

d) Em todas as dimensóes observa-se que os aspectos a serem aprimorados são mais relacionados à Universidade e não ao curso (MERCOSUL, 2011d). 
Verifica-se nas dimensões projeto acadêmico e comunidade universitária que alguns critérios foram parcialmente cumpridos pelo curso, contudo esses critérios não são explicitados. Percebe-se também que na transcrição que não há informaçôes acerca da avaliação da dimensão infraestrutura, embora conste no documento uma observação sobre a necessidade de aprimoramento de aspectos relacionados à universidade. Nesse sentido, permanecem dúvidas sobre como e em que medida o curso acreditado atendeu aos documentos de critérios do Arcu-Sul.

Essa inconsistência também está presente nas características apontadas para as dimensóes projeto acadêmico e comunidade universitária dos cursos paraguaios de engenharia, medicina e medicina veterinária, uma vez que, de acordo com os documentos, esses cursos cumprem com a maioria dos critérios de qualidade das referidas dimensôes, no entanto, esses critérios não são especificados. $\mathrm{O}$ caso do curso de odontologia pode ser considerado mais complexo, conforme indicado na citação a seguir:

a) Contexto institucional:

Teniendo en cuenta los juicios realizados y las acciones encaminadas a garantizar la calidad en forma permanente, entre otros, permiten considerar que cumple con la mayoría de los critérios de calidad de los componentesde la Dimensión Contexto Institucional.

b) Proyecto académico:

Teniendo em cuenta las observaciones y juicios realizados se considera que la carrera cumple minimamente con los critérios de calidad estabelecidos para la Dimensión Proyecto Académico.

c) Comunidad Universitaria:

Teniendo em cuenta las observaciones y juicios realizados se considera que la carrera cumple com la mayoría de los critérios de calidad estabelecidos para la Dimensión Comunidad Universitaria.

d) Infraestructura:

Teniendo em cuenta las observaciones y juicios realizados se considera que la carrera cumple minimamente con los critérios de calidad estabelecidos para la Dimensión Infraestructura (MERCOSUL, 2011a, p. 2-3). 
Verifica-se, além da inconsistência sobre quais os componentes e critérios foram cumpridos nos processos de avaliação, que o curso de odontologia paraguaio não atende totalmente às exigências dos documentos do Arcu-Sul em nenhuma das dimensóes. E, no que tange às dimensóes projeto acadêmico e infraestrutura, o curso cumpriu apenas com o mínimo estabelecido pelo Sistema.

Desse modo, pode-se notar que a agência paraguaia constituiu seus próprios parâmetros de análise, uma vez que a imprecisão dos critérios definidos pelo Sistema, permite interpretações diversas.

Cumpre lembrar que as agências argentina e brasileira utilizaram suas experiências em avaliação e buscaram enfatizar, nas resoluçóes de acreditação, os potenciais dos seus sistemas, por meio das informaçôes dos cursos e das instituiçóes, o que denotou diferenças importantes nos resultados do processo de acreditação. Nesses casos, a acreditação regional está certificando a qualidade de cursos já avaliados pelos sistemas nacionais, ou seja realizando uma avaliação da avaliação (SOUZA, 2016).

Ressalta-se que as agências dos dois países enfatizaram, nas resoluçóes, a existência de aspectos políticos importantes para o SEM, como exemplo, a mobilidade e o intercâmbio do curso argentino de medicina e o compromisso social do curso brasileiro de medicina, explicitado no trecho abaixo:

[...] a UFRGS é uma universidade pública, gratuita, plural e comprometida com o Brasil contemporâneo. Além disso, o Plano de Gestáo da Administração Central preconiza a construção de um país desenvolvido e socialmente justo através da atividade universitária. A busca da excelência, com inclusão social, deve levar a Universidade a se constituir como elemento de irradiação de formação humana, para além das fronteiras do Brasil (MERCOSUL, 2014, p. 2).

É necessário mencionar que a mobilidade, o intercâmbio e a acessibilidade na infraestrutura são aspectos mencionados nos documentos de critérios, uma vez que sáo importantes para o atendimento da missáo e da finalidade do SEM. Contudo, não constam em todos os documentos analisados. 
Desse modo, é necessário problematizar o fato de cursos que não atendem nem mesmo aos critérios definidos pelo Arcu-Sul receberem um resultado positivo do processo de acreditação e, dessa forma, representarem a qualidade regional.

Registra-se também que o Manual de Procedimentos do Sistema afirma que a garantia da qualidade exige o controle e o acompanhamento das açóes de melhoria que foram planejadas desde o processo de autoavaliação. Entretanto, as agências de acreditação não priorizaram, nos documentos, os problemas detectados e as sugestóes de melhoria dos cursos.

Essas constataçóes mostram que a Rana encontrou dificuldades para coordenar o Sistema e definir a qualidade regional. Assim, seu conceito é estabelecido pelos processos de avaliação realizados, considerados suficientes para justificar a certificação da qualidade pelo Mercosul.

Os dados evidenciam a predominância do caráter técnico e instrumental da avaliação no processo de acreditação realizado por algumas agências, como a boliviana, que considera apenas a dimensão formal da qualidade. A dimensão política da qualidade aparece isolada nos argumentos de algumas agências de acreditação e de algumas titulaçóes, a exemplo do que ocorre com os critérios estabelecidos pelo Sistema.

Em síntese, os resultados do primeiro ciclo revelam que a qualidade regional se constitui a partir de parâmetros diversos, e, portanto, não é possível afirmar sobre a existência de um padrão único de qualidade para todos os cursos acreditados e que esteja acima da qualidade nacional dos países integrantes do Sistema, conforme preconiza o SEM.

\section{Consideraçóes}

Para atender às finalidades do Mercosul, especialmente aquelas voltadas à capacitação de recursos humanos para impulsionar o desenvolvimento do bloco, o Arcu-Sul adota uma concepção de qualidade vinculada à competição de mercado. Diante desse conceito, foram estabelecidos os parâmetros de qualidade regional, que refletem os propósitos da educaçáo superior e, consequentemente, o projeto de sociedade que se busca construir.

Nos documentos do primeiro ciclo do Sistema, pode-se apreender que existem variaçóes na acreditação que perpassam desde a ênfase na di- 
mensão formal até a dimensão política da qualidade. Desse modo, percebem-se concepçóes distintas entre o preconizado pela política regional e os resultados divulgados pelas agências nacionais de acreditação, o que pode explicar algumas incongruências apontadas na implementação do Sistema, como a heterogeneidade das resoluções de acreditação, no que diz respeito não só ao modelo e à quantidade de informaçôes, mas, principalmente, ao conteúdo dos documentos.

Pode-se inferir que a dimensão política e social da educação não é prioridade na implementação da acreditaçáo regional, processo que teria como prerrogativa a garantia e a melhoria da qualidade. E, considerando o caráter competitivo da acreditação e do seu modelo de avaliação, alguns países acabam optando por cumprir formalmente os critérios estabelecidos no âmbito regional. Nesses casos, a avaliação passa a ser utilizada para reunir os elementos necessários para atingir os possíveis efeitos regulatórios do Sistema, ou seja, o reconhecimento automático de títulos nos países do Mercosul.

\section{Notas}

1 Registra-se que, para este trabalho, considera-se a acreditação como a "[...] ação ou resultado de acreditar, de atestar oficialmente a boa qualidade de algo: certificado de acreditação” (GEIGER, 2012, p.15).

2 Barroso (2005) expóe que a regulação enquanto modo de coordenaçáo dos sistemas educativos é um processo que tem por principal função assegurar o equilíbrio, a coerência, mas também a transformação desse mesmo sistema. Na análise do autor, "o processo de regulação compreende, não só, a produção de regras (normas, injunçôes, constrangimentos etc.) que orientam o funcionamento do sistema, mas também o (re) ajustamento da diversidade de acçôes dos actores em função dessas mesmas regras" (BARROSO, 2005, p. 733).

3 O Acordo sobre a criação e implementação de um sistema de acreditação de cursos de graduação para o reconhecimento regional da qualidade acadêmica dos respectivos diplomas no MERCOSUL e Estados Associados foi assinado em San Miguel de Tucumán, na República Argentina, em junho de 2008, e homologado pela Decisão CMC no 17/2008.

4 Nesse sentido consultar: http://sistemaarcusul.mec.gov.br/arcusul/pages/pesquisaexterna/pesquisarCursoExterno.seam. Acesso em 11 nov. 2015.

\section{Referências}

AFONSO, Almerindo Janela. Mudanças no Estado-avaliador: comparativismo internacional e teoria da modernização revisitada. Revista Brasileira de Educação, v. 18, n. 53, p. 267-284, abr./jun. 2013. 
AZEVEDO, Janete Maria Lins de. A educação como política pública. Campinas: Autores Associados, 1997.

BELLONI, Isaura et al. Avaliação institucional na Universidade de Brasília. In: BALZAN, Newton César; DIAS SOBRINHO, José (Orgs.). Avaliação institucional: teoria e experiências. 2. ed. Sáo Paulo: Cortez, 2000.

CUNHA, Maria Isabel da. A qualidade e ensino de graduação e o complexo exercício de propor indicadores: é possível obter avanços? Avaliação, Campinas, v. 19, n. 2, p. 453-462, jul. 2014.

DEMO, Pedro. Avaliação qualitativa. Campinas: Autores Associados, 2015.

DEMO, Pedro. Educação e qualidade. Campinas: Papirus, 1994.

DIAS SOBRINHO, José. Avaliação: políticas educacionais e reformas da educação superior. São Paulo: Cortez, 2003.

DIAS SOBRINHO, José. Qualidade, avaliação: do Sinaes a índices. Avaliação, Campinas, v. 13, n. 3, p. 817-825, nov. 2008.

DOURADO, Luiz Fernandes; OLIVEIRA, João Ferreira de. A qualidade da educação: perspectivas e desafios. Cad. Cedes, Campinas vol. 29, n. 78, p. 201-215, maio/ago. 2009. Disponível em: http://www.cedes.unicamp.br.

ENGUITA, Mariano Fernández. O discurso da qualidade e a qualidade do discurso. In: GENTILI, Pablo; SILVA, Tomaz Tadeu da (Orgs.). Neoliberalismo, qualidade total e educação: visóes críticas. Petrópolis: Vozes, 1994. p. 93-110.

GEIGER, Paulo (Org.). Caldas Aulete: dicionário escolar da língua portuguesa. Rio de Janeiro: Lexikon, 2012.

GRAMSCI, Antonio. Obras escolhidas. Lisboa: Estampa, 1974.

GRIBOSKI, Cláudia Maffini; FUNGHETTO, Suzana Schwerz. A internacionalização como indicador de qualidade do Sinaes e do Sistema ARCU-SUL. In: CUNHA, Célio da; SOUSA, José Vieira de; SILVA, Maria Abádia da (Orgs.). Internacionalização da educação: discursos, práticas e reflexos sobre as políticas educativas. 1. ed. Belo Horizonte: Fino Traço, 2016. p. 243-261.

KNIGHT, Jane. Comercialización de servicios de educación superior: implicaciones del AGCS. In: GUADILLA, Carmem Garcia (Ed.). El difícil equilibrio: la educación superior entre bien público y comercio de servicios. Implicaciones del AGCS (GATS). Paris: [s.n.], 2004. 107 p.

KRAWCZYK, Nora; SANDOVAL, Salvador Antonio Mireles. O processo de regionalização das universidades do Mercosul: um estudo exploratório de regulação supranacional e nacional. Educação e Realidade, Porto Alegre, v. 37, n. 2, p. 647-668, 2012. 
LAMARRA, Norberto Fernández. La convergencia de la educación superior em América Latina y su articulación con los espacios europeo e ibero-americano: Posibilidades y límites. Avaliação, Campinas, v. 15, n. 2, p. 9-44, jul. 2010.

MERCOSUL. Mercado Comum do Sul. Acordo sobre a criação e implementação de um sistema de credenciamento de cursos de graduação para o reconhecimento regional da qualidade acadêmica dos respectivos diplomas no Mercosul e Estados Associados. San Miguel de Tucumán, Mercosul Educacional, 2008a. Disponível em: http://edu. mercosur.int/arcusur/index.php/pt-br/acordo-de-criacao. Acesso em: 10 set. 2014.

MERCOSUL. Mercado Comum do Sul. Acreditação Regional de Cursos Universitários MERCOSUL. Mercosul Educacional, 2016. Disponível em: http://edu. mercosur.int/arcusur/index.php/pt-br/. Acesso em: 25 maio 2016.

MERCOSUL. Mercado Comum do Sul. Agencia Nacional de Evaluación y Acreditación de la Educación Superior. Acuerdo de Acreditación no 14/2011. Carrera de Medicina de la Universidad Nacional de Itapuá. Sistema ARCU-SUL, 2011a, 4 p. Disponível em: http://sistemaarcusul.mec.gov.br/arcusul/pages/pesquisaexterna/ pesquisarCursoExterno.seam\#tabelaCursos. Acesso em: 11 nov. 2015.

MERCOSUL. Mercado Comum do Sul. Comisión Nacional de Acreditación de Acreditación de Carreras Universitarias (CNACU). Resolución no 009/2011. Carrera de Ingeniería Agronómica de la Universidad Autónoma Juan Misael Saracho de Tarija, Tarija. Sistema ARCU-SUL, 2011b. Disponível em: http://sistemaarcusul.mec.gov.br/ arcusul/pages/pesquisaexterna/pesquisarCursoExterno.seam\#tabelaCursos. Acesso em: 11 nov. 2015.

MERCOSUL. Mercado Comum do Sul. Comissão Nacional de Avaliação da Educação Superior. Acreditação no 107898. Curso de Medicina da Universidade Federal do Rio Grande do Sul, Porto Alegre. Sistema ARCU-SUL, 2014, 7 p. Disponível em: http:// sistemaarcusul.mec.gov.br/arcusul/pages/pesquisaexterna/pesquisarCursoExterno. seam\#tabelaCursos. Acesso em: 11 nov. 2015.

MERCOSUL. Mercado Comum do Sul. Sistema de Acreditação Regional de Cursos Universitários do Mercosul. Manual de Procedimentos do Sistema. [S.1.]: Sistema ARCU-SUL, 2008b, 10 p. Disponível em: http://edu.mercosur.int/arcusur/images/pdf/ manual_procedimentos_pt.pdf. Acesso em: 12 abr. 2015.

MERCOSUL. Mercado Comum do Sul. Sistema de Acreditación Regional de Carreras Universitarias. Guia de Autoevaluación para carreras de Agronomía. [S.1.]: Sistema ARCU-SUR, 2008c. Disponível em: http://edu.mercosur.int/arcusur/images/pdf/guia/ guia_auto_pt_\%20agronomia.pdf. Acesso em: 06 nov. 2014.

NEAVE, Guy. O Estado-avaliador como política em transição: um estudo histórico e anatômico. In: COWEN, Robert; KAZAMIAS, Andreas M.; ULTERHALTER, Elaine (Orgs.). Educação comparada: panorama internacional e perspectivas. Brasília: Unesco, Capes, 2012. p. 675-696. 
REAL, Giselle Cristina Martins. Avaliação e qualidade no Ensino Superior: os impactos do período 1995-2002. Educação e Pesquisa, São Paulo, v. 35, n. 3, p. 573-584, set./dez. 2009.

SANTOS, Boaventura de Sousa. A universidade do século XXI: para uma reforma democrática e emancipatória da universidade. 3 ed. São Paulo: Cortez, 2011.

SOUSA, José Vieira de. Qualidade na educação superior: lugar e sentido na relação público-privado. Cad. Cedes, Campinas, v. 29, n. 78, p. 242-256, maio/ago. 2009.

SOUZA, Mary Ane de. Concepções de qualidade na educação superior: interseção entre os instrumentos de avaliaçáo do Mercosul e do Brasil. 2016. Dissertação (Mestrado em Educação) - Universidade Federal da Grande Dourados, Dourados, 2016.

VERHINE, Robert Evan; FREITAS, Antônio Alberto da Silva Monteiro. A avaliação da educação superior: modalidades e tendências no cenário internacional. Revista Ensino Superior Unicamp, v. 3, n. 7, p. 16-39, 2012.

Recebido em 5 ago. 2019 / Aprovado em I7 dez. 2019

Para referenciar este texto:

SOUZA, M. P.; REAL, G. C. M. Qualidade regional revelada pelo Sistema de Acreditação de Cursos Universitários do Mercosul. EccoS - Revista Científica, São Paulo, n. 5I, eI4548, out./dez. 2019. Disponível em: https://doi.org/I0.5585/EccoS. n5I.I 4548 . 